\title{
High Velocity Impact and Blast Loading of Composite Sandwich Panels with Novel Carbon and Glass Construction
}

\author{
E. Rolfe ${ }^{1} \cdot$ C. Kaboglu ${ }^{1} \cdot$ R. Quinn ${ }^{1} \cdot$ P. A. Hooper ${ }^{1} \cdot$ H. Arora ${ }^{1,2} \cdot$ J. P. Dear ${ }^{1}$
}

Received: 22 March 2018 / Accepted: 26 June 2018 / Published online: 10 July 2018

(c) The Author(s) 2018

\begin{abstract}
This research investigates whether the layup order of the carbon-fibre/glass-fibre skins in hybrid composite sandwich panels has an effect on impact response. Composite sandwich panels with carbon-fibre/glass-fibre hybrid skins were subjected to impact at velocities of $75 \pm 3$ and $90 \pm 3 \mathrm{~m} \mathrm{~s}^{-1}$. Measurements of the sandwich panels were made using high-speed 3D digital image correlation (DIC), and post-impact damage was assessed by sectioning the sandwich panels. It was concluded that the introduction of glass-fibre layers into carbon-fibre laminate skins reduces brittle failure compared to a sandwich panel with carbon-fibre reinforced polymer skins alone. Furthermore, if the impact surface is known, it would be beneficial to select an asymmetrical panel such as Hybrid-(GCFGC) utilising glass-fibre layers in compression and carbon-fibre layers in tension. This hybrid sandwich panel achieves a specific deflection of $0.322 \mathrm{~mm} \mathrm{~kg}{ }^{-1} \mathrm{~m}^{2}$ and specific strain of $0.077 \% \mathrm{~kg}^{-1} \mathrm{~m}^{2}$ under an impact velocity of $75 \pm 3 \mathrm{~m} \mathrm{~s}^{-1}$. However, if the impact surface is not known, selection of a panel with a symmetric yet more dispersed hybridisation would be effective. By distributing the different fibre layers more evenly within the skin, less surface and core damage is achieved. The distributed hybrid investigated in this research, Hybrid-(GCGFGCG), achieved a specific deflection of $0.394 \mathrm{~mm} \mathrm{~kg}{ }^{-1} \mathrm{~m}^{2}$ and specific strain of $0.085 \% \mathrm{~kg}^{-1} \mathrm{~m}^{2}$ under an impact velocity of $75 \pm 3 \mathrm{~m} \mathrm{~s}^{-1}$. Blast loading was performed on a large scale version of Hybrid-(GCFGC) and it exhibited a maximum deflection of $75 \mathrm{~mm}$ following a similar deflection profile to those observed for the impact experiments.
\end{abstract}

Keywords Impact $\cdot$ Blast $\cdot$ Hybrid composite $\cdot$ Composite sandwich

\section{Introduction}

Composite sandwich panels have many advantageous properties, which make them an attractive choice for many applications within the aerospace, naval and wind turbine sectors. These properties include high strength-to-weight ratio and low radar signature. The ability to tailor composite materials for a particular type of expected loading is a major benefit as composite sandwich structures are often subjected to particularly demanding loads including high strain rate loading and impact loading. Naval structures may also undergo blast loading and wave slamming.

E. Rolfe

emily.rolfe11@imperial.ac.uk

1 Department of Mechanical Engineering, Imperial College London, South Kensington Campus, London SW7 2AZ, UK

2 Zienkiewicz Centre for Computational Engineering, College of Engineering, Swansea University, Bay Campus, Swansea SA1 8EN, UK
Karthikeyan et al. impacted carbon-fibre reinforced polymer (CFRP) and Ultra high molecular weight Polyethylene (UHMWPE) monolithic laminates with metal foam projectiles at velocities between 140 and $890 \mathrm{~m} \mathrm{~s}^{-1}$ [1]. Karthikeyan et al. found that the UHMWPE beams outperformed the CFRP beams by exhibiting a lower central deflection and higher failure impulse. Different fibrous materials can be combined to create hybrid composites, which incorporate the advantageous attributes of both materials [2]. The materials can be combined layer-by-layer (interlaminar), within layers in a weave (intralaminar) or within the yarn (intrayarn) [3]. If the two constituent materials are combined in the correct ratios, gradual failure of the material over increasing strain can be achieved [2]. Furthermore, the location of different layers in an interlaminar hybrid can be tailored so that the composite is optimised to resist a load from a particular direction.

The hybridisation of UHMWPE with carbon-fibres was also performed by Bouwmeester et al. and the hybrids were subjected to quasi-static characterisation in addition 
to falling dart impact tests [4]. The hybrid composites demonstrated a significant improvement under impact. Flexural strength and stiffness of the composite remains constant up to 50\% UHMWPE fibre content when normalised by density of the composite. Low velocity impact on hybrid composite laminates has been carried out by Enfedaque et al. and Sevkat et al. [5, 6]. Enfedaque et al. and Sevkat et al. used drop towers to impact the specimens. Enfedaque et al. elected to investigate impact energies between 30 and $245 \mathrm{~J}$ whilst Sevkat et al. investigated projectile velocities of $3.9-6.3 \mathrm{~m} \mathrm{~s}^{-1}[5,6]$. Enfedaque et al. and Sevkat et al. both concluded that penetration impact resistance of carbon-fibre and glass-fibre hybrid laminates was improved when glass-fibre fabrics were the outermost layers. Sevkat et al. also carried out repeated impact tests at $3.9 \mathrm{~m} \mathrm{~s}^{-1}$ and found that damage build up and accumulation was also reduced when glass-fibre layers were added and especially when they were added as outside layers [7]. Many researchers agree that if the fibres with highest energy absorption potential are placed as the outermost layers, the hybrid composite is able to absorb more energy [3]. In addition, the damage experienced by the hybrid composites contributes to the amount of energy they can absorb during impact. Sevkat et al. showed that the damaged area in carbon-fibre/glass-fibre hybrids was greater than the areas in either of the constituent composites [7]. The delaminations between the layers was due to the incompatibility between the carbon-fibre and glassfibre properties.

Pandya et al. investigated the ballistic impact behaviour, in particular the ballistic limit velocity, of hybrid carbonfibre and glass-fibre composite laminates [8]. For a constant laminate thickness, the ballistic limit can be increased by incorporating glass-fibre layers into the carbon-fibre laminate. A higher ballistic limit was achieved by placing carbonfibre layers between the glass-fibre layers compared to the inverse. For constant areal density, however, the carbon-fibre laminate achieved the highest ballistic limit followed by the glass-fibre laminate and then the hybrid composites. Reddy et al. also subjected carbon-fibre and glass-fibre hybrid laminates to high velocity impact against a mild steel projectile fired from an AK-47 rifle at a $10 \mathrm{~m}$ stand-off [9]. Reddy et al. concluded that a laminate that incorporated 50:50 in weight of the two fibres demonstrated maximum energy absorption. Randjbaran et al. subjected glass-fibre/aramid-fibre/carbonfibre hybrid composite laminates to ballistic impact using a gas gun to fire a steel projectile at $182 \mathrm{~m} \mathrm{~s}^{-1}$ [10]. The composite layup was varied to see the effect the stacking sequence has on energy absorption. The results showed that a glass-fibre layer at the front, experiencing the impact, is beneficial and a carbon-fibre layer at the rear is detrimental to the panel performance. The knowledge drawn from high and low velocity impact of hybrid composite laminates could be highly advantageous when hybrid laminates are utilised as the skins of composite sandwich panels.

As discussed, a large body of research exists for the high velocity impact performance of composite laminates, including hybrid composite laminates. However, the performance of composite sandwich panels with polymeric foam cores under dynamic impact is of interest in many sectors and is hence the topic under investigation in this research.

Composite sandwich panels with varying face-sheet configurations have been tested under full scale blast loading. Arora et al. subjected panels $1.7 \mathrm{~m} \times 1.5 \mathrm{~m}$ in size to a $100 \mathrm{~kg}$ nitromethane charge from a stand-off distance of $14 \mathrm{~m}$ to compare the response of a composite sandwich panel with glass-fibre reinforced polymer (GFRP) facesheets to one with carbon-fibre reinforced polymer (CFRP) face-sheets [11]. Both panels suffered from skin failure, the GFRP panel developed a large vertical front face-sheet crack and the CFRP panel suffered from cracks initiating at the bolt holes. The CFRP panels exhibited a lower out-of-plane deflection compared to the GFRP panels, however, further underwater blast testing has revealed that a CFRP panel suffers catastrophic brittle failure in this loading regime [12]. This indicates that a panel with solely CFRP skins may not be suitable under all the types of loading experienced by a naval vessel. In addition, composite sandwich panels with glass-fibre and hybrid glass-fibre/aramid-fibre skins were also subjected to a $1 \mathrm{~kg}$ underwater blast test by Arora et al. [13]. The hybrid glass/aramid panel suffered from severe skin damage on the front and rear skins and the panel core was crushed significantly. Arora et al. concluded that the replacement of some glass-fibre plies with aramid-fibre plies lessened the skin properties rather than enhancing them indicating that this combination is not an effective hybrid for this type of loading. Composite sandwich panels with hybrid skins have been shown to be beneficial in some cases. Kelly et al. performed large scale blast testing on panels with GFRP skins and polypropylene (PP) interlayers [14]. The panel with PP interlayers had no front skin cracks compared to a panel with solely GFRP skins. Polymer interlayers have been investigated by other researchers for their beneficial properties against shock loading. Shock tube loading on sandwich panels with polymeric foam cores and glass-fibre skins with polyurea (PU) interlayers has been performed by Gardner et al. [15]. The specimen were subjected to a shock load with $\sim 1.0 \mathrm{MPa}$ incident peak pressure. The location of the PU layer was varied and it was found to affect deflection and strain of the sandwich panels. Placing the PU layer between the core and the rear skin reduced deflection and strain and hence would maintain structural integrity of the panel.

This paper investigates how composite sandwich panels with polymeric foam core and hybrid carbon-fibre and glass-fibre skins perform under high velocity impact testing. 
Following this, the best hybrid composite sandwich panel was selected to undergo blast loading to understand its behaviour under pressure loading encountered during blast.

\section{Materials}

Composite sandwich panels with carbon-fibre and glass-fibre hybrid skins were manufactured using vacuum assisted resin transfer moulding (VARTM). Three types of hybrid were compared against a benchmark carbon-fibre (CFRP) sandwich panel and a benchmark glass-fibre (GFRP) sandwich panel. All panels had a $20 \mathrm{~mm}$ polyethylene terephthalate (PET) foam core and approximately $2 \mathrm{~mm}$ thick skins made from 8 plies of continuous fibre fabrics oriented to create a quadriaxial layup $[0,90,+45,-45]_{2} \operatorname{CORE}[-45,+45,90$, $0]_{2}$. The CFRP panel had ten plies of continuous fibre fabrics to give the panels a comparable areal density. By increasing the ply count in the CFRP panel from 8 to 10 plies, the stiffness of the panel was increased by $3.55 \mathrm{kN} \mathrm{m}^{-1}$. The increase in stiffness would reduce the panel deflection but at the expense of brittle failure. Since the stiffness of each panel would vary due to the location of the carbon-fibre and glass-fibre layers, areal density was selected as the consistent

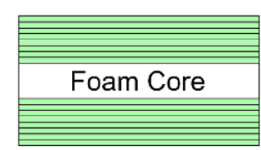

GFRP

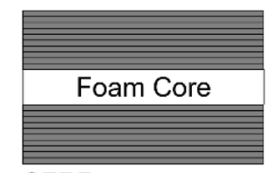

CFRP

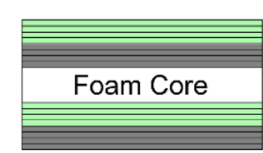

HYBRID-(GCFGC)

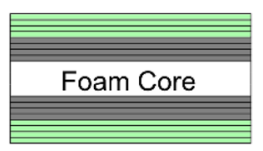

HYBRID-(GCFCG)

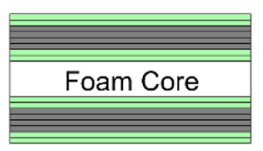

HYBRID-(GCGFGCG)
Fig. 1 Layup schematic of the five composite sandwich panels fabricated property. The sandwich panel configurations are shown in Fig. 1. As a result of the impact experiments, detailed later, Hybrid-(GCFGC) was selected for full-scale blast testing. A large $1.5 \times 1.7 \mathrm{~m}$ panel was fabricated with the same skin layups on a $30 \mathrm{~mm}$ polyvinyl chloride (PVC) foam core.

Quadriaxial 8 ply GFRP and CFRP face-sheet laminates, using identical fibres to those used in the sandwich panel skins, were characterised under tension and flexure at a quasi-static rate (QS). Properties of these composite laminates along with properties of the foam and resin system used during fabrication are detailed in Table 1. The configuration for Hybrid(GCFGC) was selected to take advantage of the high tensile strength of carbon-fibre. When the panel is impacted from the top, the glass-fibre layers will experience compression whilst carbon-fibre layers experience tension. The ABCD stiffness matrix for Hybrid-(GCFGC) is shown in Eq. 1. The B and C matrices are non-zero as the sandwich panel is asymmetric. When the D matrix components are compared to those of the GFRP and CFRP panels, in Eqs. 2 and 3 respectively, it is evident that the hybrid panel stiffness lays between that of the benchmark panels. The asymmetry of the Hybrid-(GCFGC) causes coupling between stretching and bending which results in greater panel strains. Therefore, Hybrid-(GCFCG) was designed using the same principle yet with a symmetrical layup to avoid this coupling. Additionally, either surface of Hybrid(GCFCG) could be the impact surface as glass-fibre is present on the outermost layer of each face. The stiffness matrix for Hybrid-(GCFCG) is shown in Eq. 4. The components of both the $\mathrm{A}$ and $\mathrm{D}$ matrices for this symmetric hybrid are lower than for the asymmetric hybrid, indicating a reduced stiffness and strength. The benefits of a symmetrical of the panel, however, may counteract this reduction. Hybrid-(GCGFGCG) aimed to result in gradual skin failure. In theory, the lower strain to failure of the carbon-fibre layers should result in their fracture and then delamination between the carbon and glass-fibre layers should occur [2]. These failure mechanisms would result in a large amount of energy absorption during impact. The ABCD matrix for this hybrid panel, shown in Eq. 5, demonstrates that

Table 1 Properties of fibre reinforcement and foam used in composite sandwich panels

\begin{tabular}{|c|c|c|c|c|c|}
\hline Material & $\begin{array}{l}\text { Density } \\
\left(\mathrm{kg} \mathrm{m}^{-3}\right)\end{array}$ & $\begin{array}{l}\text { Elastic Modulus } \\
(\mathrm{GPa})\end{array}$ & $\begin{array}{l}\text { Tensile fracture } \\
\text { stress (MPa) }\end{array}$ & $\begin{array}{l}\text { Tensile strain at } \\
\text { failure }(\%)\end{array}$ & $\begin{array}{l}\text { Flexural } \\
\text { strain at } \\
\text { failure (\%) }\end{array}$ \\
\hline Glass-fibre/Prime 20 LV 8 ply skin & $1460^{\mathrm{a}}$ & 11.6 & 347 & 2.22 & 3.52 \\
\hline Carbon-fibre/Prime 20 LV 8 ply skin & $1778^{\mathrm{b}}$ & 21.3 & 568 & 1.73 & 2.40 \\
\hline Gurit Prime 20 LV epoxy and slow hardener & $1144^{\mathrm{c}}$ & $3.5^{\mathrm{c}}$ & $73^{c}$ & - & - \\
\hline PET Foam & $150^{\mathrm{d}}$ & $0.185^{\mathrm{d}}$ & $3.3^{\mathrm{d}}$ & - & - \\
\hline
\end{tabular}

${ }^{\mathrm{a}}$ Glass-fibre density taken from [17]

${ }^{\mathrm{b}}$ Carbon-fibre density taken from [18]

${ }^{\mathrm{c}}$ Resin properties taken from [16]

${ }^{\mathrm{d}}$ Foam properties taken from [19] 
the panel again has reduced stiffness compared to the other two hybrids. This stiffness reduction may enable the panel to undergo greater deflection and energy absorption. As widely agreed in literature, composites are able to absorb more energy overall if the fibres with highest energy absorption potential are placed as the outermost layers [3, 7]. In all the hybrids, therefore, glass-fibres layers were placed as the outermost layer that would experience the projectile impact. The composite sandwich panels were infused using Gurit Prime $20 \mathrm{LV}$ epoxy and slow hardener during the VARTM process. The panels were cured by following the recommended cure cycle [16]. Density and stiffness of the five sandwich panels subjected to impact are detailed in Table 2.

Hybrid-(GCFGC) $\left[\begin{array}{cccccc}128 & 41.9 & 4.6 & 0 & 0 & 28.7 \\ 41.9 & 128 & 4.6 & 0 & 0 & 28.7 \\ 4.6 & 4.6 & 43.0 & 28.7 & 28.7 & 0 \\ 33.3 & 11.1 & 52.8 & 9110 & 2870 & 363 \\ 11.1 & 33.3 & 52.8 & 2870 & 8980 & 363 \\ 52.8 & 52.8 & 11.1 & 363 & 363 & 2950\end{array}\right] \times 10^{9} \mathrm{Nm}$

GFRP $\left[\begin{array}{cccccc}79.7 & 25.8 & 0 & 0 & 0 & 0 \\ 25.8 & 79.7 & 0 & 0 & 0 & 0 \\ 0 & 0 & 26.9 & 0 & 0 & 0 \\ 0 & 0 & 0 & 5790 & 1810 & 18.2 \\ 0 & 0 & 0 & 1810 & 5720 & 18.2 \\ 0 & 0 & 0 & 18.2 & 18.2 & 1890\end{array}\right] \times 10^{9} \mathrm{Nm}$

CFRP $\left[\begin{array}{cccccc}202 & 52.1 & 0 & 0 & 0 & 0 \\ 52.1 & 202 & 0 & 0 & 0 & 0 \\ 0 & 0 & 53.0 & 0 & 0 & 0 \\ 0 & 0 & 0 & 14900 & 3810 & 39.4 \\ 0 & 0 & 0 & 3810 & 14900 & 39.4 \\ 0 & 0 & 0 & 39.4 & 39.4 & 3880\end{array}\right] \times 10^{9} \mathrm{Nm}$

Table 2 Properties of the five hybrid sandwich panels

\begin{tabular}{lccl}
\hline Panel type & $\begin{array}{l}\text { Areal } \\
\text { density } \\
\left(\mathrm{kg} \mathrm{m}^{-2}\right)\end{array}$ & $\begin{array}{l}\text { Equivalent bending } \\
\text { stiffness }\left(\mathrm{kN} \mathrm{m}^{-2}\right)\end{array}$ & $\begin{array}{l}\text { Fibre } \\
\text { volume } \\
\text { fraction }\end{array}$ \\
\hline GFRP & 9.42 & 8.08 & 0.36 \\
CFRP & 10.08 & 15.91 & 0.33 \\
HYBRID-(GCFGC) & 9.04 & 10.47 & 0.36 \\
HYBRID-(GCFCG) & 9.04 & 11.02 & 0.33 \\
$\begin{array}{l}\text { HYBRID- } \\
\text { (GCGFGCG) }\end{array}$ & 9.04 & 9.41 & 0.39 \\
\hline
\end{tabular}

Hybrid-(GCFCG) $\left[\begin{array}{cccccc}127 & 41.8 & 0 & 0 & 0 & 0 \\ 41.8 & 127 & 0 & 0 & 0 & 0 \\ 0 & 0 & 42.6 & 0 & 0 & 0 \\ 0 & 0 & 0 & 9030 & 2850 & 35.2 \\ 0 & 0 & 0 & 2850 & 8890 & 35.2 \\ 0 & 0 & 0 & 35.2 & 35.2 & 2910\end{array}\right] \times 10^{9} \mathrm{Nm}$

Hybrid-(GCGFGCG) $\left[\begin{array}{cccccc}126 & 41.1 & 0 & 0 & 0 & 0 \\ 41.1 & 126 & 0 & 0 & 0 & 0 \\ 0 & 0 & 42.4 & 0 & 0 & 0 \\ 0 & 0 & 0 & 8650 & 2810 & 29.3 \\ 0 & 0 & 0 & 2810 & 8540 & 29.3 \\ 0 & 0 & 0 & 29.3 & 29.3 & 2900\end{array}\right] \times 10^{9} \mathrm{Nm}$

\section{Experimental}

To investigate the impact performance of the panels, experiments were performed using a gas gun apparatus. An aluminium projectile with a hemispherical nose was selected. The projectile had a diameter $24.9 \pm 0.05 \mathrm{~mm}$, length $25.45 \pm 0.05 \mathrm{~mm}$ and mass $25.5 \pm 0.2 \mathrm{~g}$. A drawing of the projectile is shown in Fig. 2. Impact velocities of $75 \pm 3$ and $90 \pm 3 \mathrm{~m} \mathrm{~s}^{-1}$ were selected as this would lead to projectile kinetic energies of $77 \pm 3$ and $100 \pm 3 \mathrm{~J}$ respectively. The higher velocity resulted in a $30 \%$ increase in projectile kinetic energy. These velocities were chosen as they would cause significant panel damage and deflection under impact but would not lead to full penetration of the panel by the projectile. The projectiles were accelerated along a $3 \mathrm{~m}$ long barrel and the velocity was measured using two pairs of infrared sensors (IR) just before the barrel exit. The end of the barrel and the sandwich panels were contained within a transparent safety box constructed from thick polycarbonate panels, aluminium extrude and steel panels.

In order to record the deflection of the panels high-speed 3D digital image correlation (DIC) was used. Two highspeed cameras (Phantom Miro LC310) were synchronised
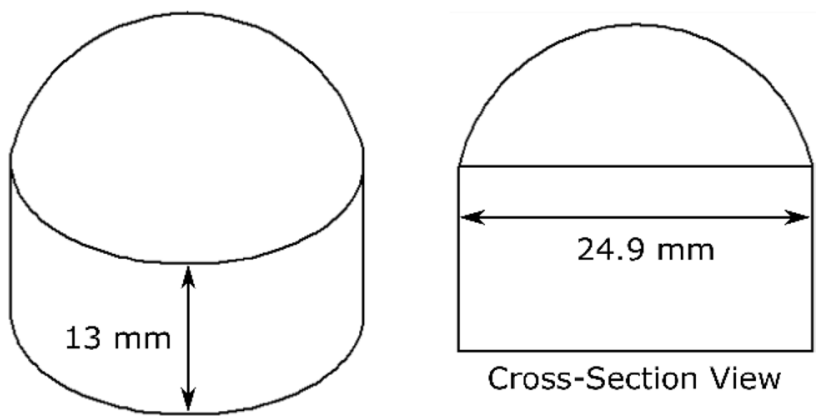

Fig. 2 Drawing showing dimensions and shape of hemispherical aluminium projectile 
and located behind the target outside the chamber. The perpendicular distance between the centre of the target and the centre of camera sensors was $970 \mathrm{~mm}$ and the two cameras were separated by a distance of $430 \mathrm{~mm}$. This gives an angle of approximately $25^{\circ}$ between the two cameras as recommended [20]. Fixed focal length lenses of $50 \mathrm{~mm}$ were used on both cameras and 39,000 frames per second were recorded following activation of the camera trigger. The trigger was activated by a signal generated by the IR sensors. During camera recording, the panels were illuminated using halogen lamps. The lamps were turned on shortly before the test to prevent any heating effects. A photograph and diagram of the experimental setup is shown in Fig. 3.

The composite sandwich panels were $160 \times 160 \mathrm{~mm}$ in size and were bolted into a steel fixture using twelve M8 bolts. The steel fixture had an opening $70 \times 70 \mathrm{~mm}$. In order to facilitate DIC, the panels were spray painted matte white and a random black speckle pattern was applied to the back surface of the panels. The DIC algorithm is then able to track each facet containing a unique speckle pattern and calculates the deformation from the sequence of images from the two high-speed cameras. The recommended speckle size is $3-5$ pixels, for the current setup this equates to $0.8 \mathrm{~mm}$. A black marker was used to create the speckles this size. Following impact loading, the panels were sectioned along the central axis and the visual damage to the panels was photographed, measured and recorded.

To investigate Hybrid-(GCFGC) under blast loading the panel was bolted into the front of a steel test cubicle. $5 \mathrm{~mm}$ thick steel frames were adhered to the front and back of the panel using a marine adhesive. The panel was secured into the front of the cubicle using $20 \times \mathrm{M} 11$ bolts around the perimeter through the steel frame. Two high speed cameras were situated behind the panel within the cubicle to capture the response of the panel. The distances between the cameras and panel were scaled up to ensure the panel was in the camera field of view whilst the $25^{\circ}$ angle between the two cameras was maintained. The panel was painted matte white and random speckles of approximately $5 \mathrm{~mm}$ in diameter were painted onto the white surface. The panels were placed at a $15 \mathrm{~m}$ stand-off distance away from a $100 \mathrm{~kg}$ nitromethane spherical charge. The charge was raised to the height of the centre of the panel. The high speed cameras were triggered upon detonation of the charge. A schematic diagram of the blast experiment setup is shown in Fig. 4 along with a photograph of the panel mounted in the cubicle.

\section{Results}

The response of the five composite sandwich panels are detailed in this section. The damage suffered by each panel following impact is then observed.

\section{High velocity impact}

The panels were subjected to impact at $75 \pm 3$ and $90 \pm 3 \mathrm{~m} \mathrm{~s}^{-1}$ to assess their performance under the two velocities. Full-field images showing the out-of-plane displacement of all five panel types, when subjected to impact velocity $75 \mathrm{~m} \mathrm{~s}^{-1}$ are shown in Fig. 5. These image series show that the GFRP and Hybrid-(GCGFGCG) panels experience the greatest deflection at this impact velocity, this is a result of the reduced panel stiffness as shown in the ABCD matrices. The CFRP panel demonstrates the lowest deflection due to its increased stiffness. Out of the hybrid panels, the Hybrid-(GCFGC) configuration demonstrates the lowest deflection due to its greater stiffness as shown in Eq. 1. More detailed results from the GFRP panel under impact velocity $75 \mathrm{~m} \mathrm{~s}^{-1}$ are shown in Fig. 6 . Figure 6a illustrates the out-of-plane displacement and major strain of the panel using contour plots calculated by DIC. The out-of-plane displacement and major strain of the centre point of the panel is plotted against time in

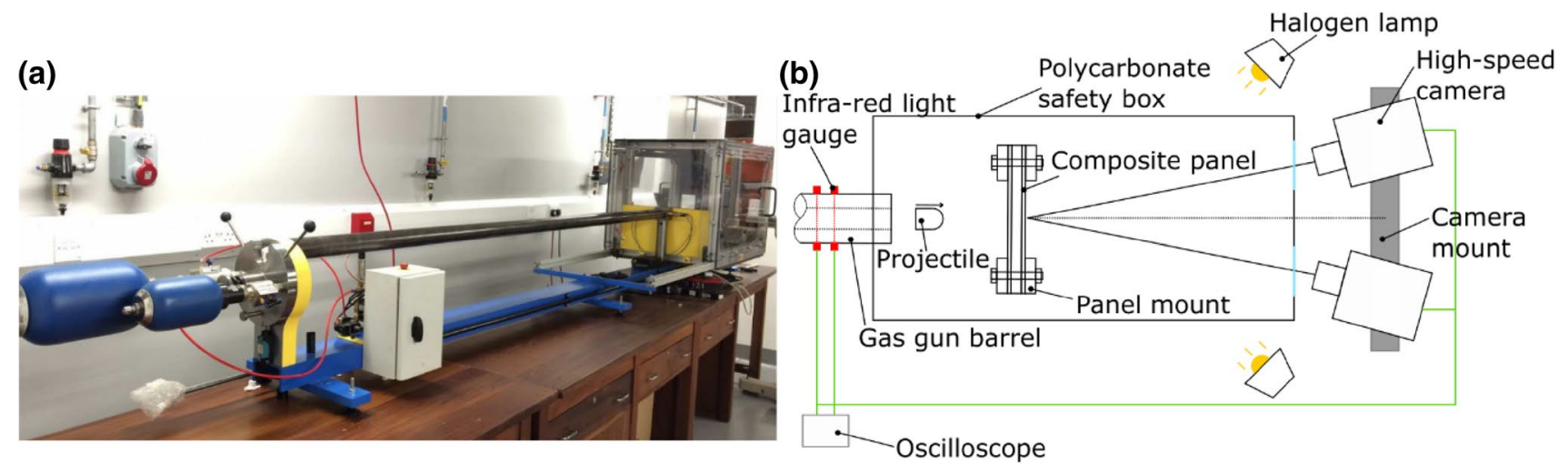

Fig. 3 Experimental gas gun set up: a photograph of gas gun, $\mathbf{b}$ diagram of the experimental set up using gas gun and high speed cameras 
Fig. 4 Experimental blast set up: a top-down diagram of the experimental set up using explosive charge, b photograph of the cubicle front (a)

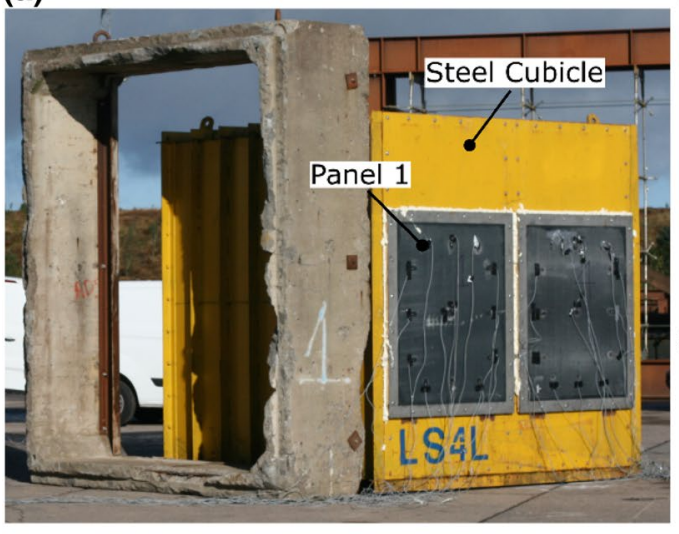

(b)
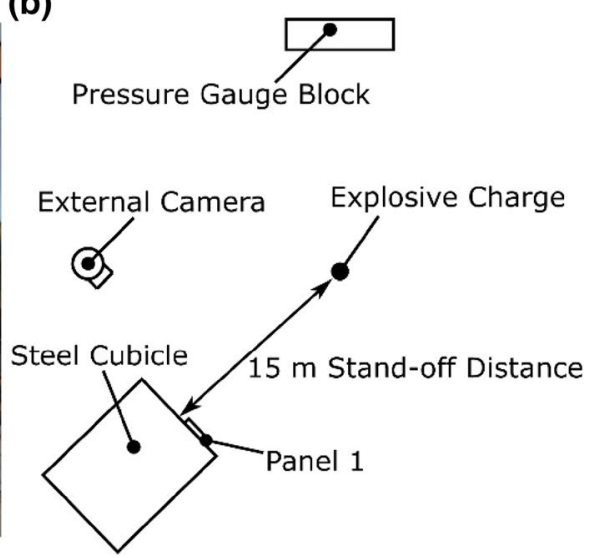

Fig. 5 Full field out-of-plane displacement from DIC for all panel types under impact velocity of $75 \pm 3 \mathrm{~m} \mathrm{~s}^{-1}$

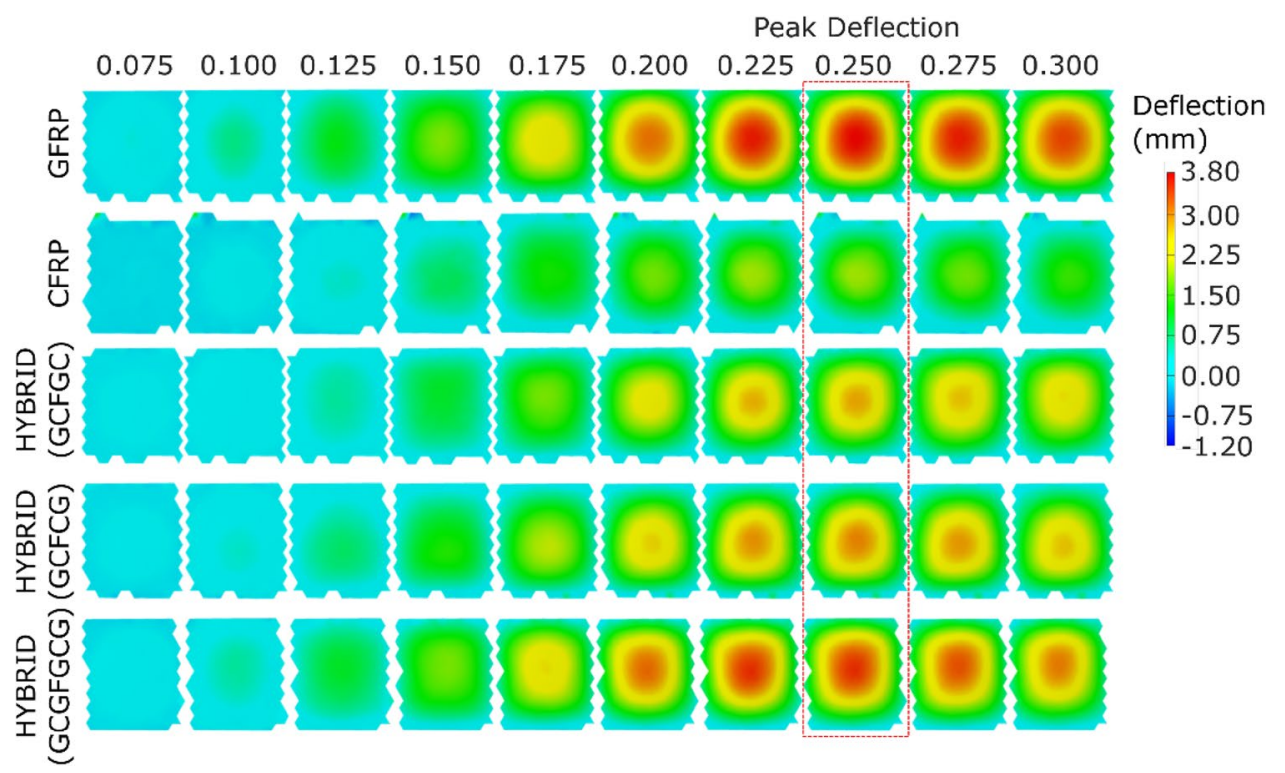

Fig. 6b. From this plot it can be seen that the maximum central displacement is $3.8 \mathrm{~mm}$, the maximum rebound displacement is $-1.2 \mathrm{~mm}$ and the time period for which the central displacement of the panel is positive is $0.5 \mathrm{~ms}$. The initial deflection and first rebound of the horizontal section of the panel are shown in Fig. 6c and d respectively. The GFRP panel subjected to $90 \mathrm{~m} \mathrm{~s}^{-1}$ impact performs similarly with a maximum deflection and maximum rebound deflection of 4.0 and $-1.6 \mathrm{~mm}$ respectively. The positive time period was also recorded as $0.5 \mathrm{~ms}$. The GFRP panels demonstrate damped oscillations following projectile impact.

The results from the Hybrid-(GCFGC) panel under impact velocity $75 \mathrm{~m} \mathrm{~s}^{-1}$ are shown in Fig. 7. Figure $7 \mathrm{a}$ shows the DIC calculated images for displacement and strain and the central line plots are shown in Fig. 7b. From this plot the maximum central displacement is $2.9 \mathrm{~mm}$. The initial deflection and first rebound of the horizontal section of the panel are shown in Fig. $7 \mathrm{c}$ and d respectively. It is clear that the panel does not rebound beyond zero before deflecting again. Under impact velocity $90 \mathrm{~m} \mathrm{~s}^{-1}$ the panel exhibits similar behaviour with maximum displacement $2.9 \mathrm{~mm}$ and no return to zero before deflecting again. Under $75 \mathrm{~m} \mathrm{~s}^{-1}$ impact, the projectile was deflected by the panel, however, at impact velocity $90 \mathrm{~m} \mathrm{~s}^{-1}$ the projectile remained embedded in the panel.

The displacement of the centre point for all panels is shown in Fig. 8. The behaviour of the Hybrid-(GCFCG) panel was similar to the Hybrid-(GCFGC) panel when subjected to impact velocity $75 \mathrm{~m} \mathrm{~s}^{-1}$. The Hybrid-(GCFCG) panel deflected by $3.1 \mathrm{~mm}$ and did not return to zero before deflecting again. Once again, the projectile was deflected off the front of the panel. Under $90 \mathrm{~m} \mathrm{~s}^{-1}$ impact, however, the panel exhibited two deflections with the second deflection greater than the initial one. The panel did not return to zero displacement between the deflections and the projectile remained embedded. The repeat experiments of this impact exhibited the same behaviour. The double deflection peak, as 
(a)
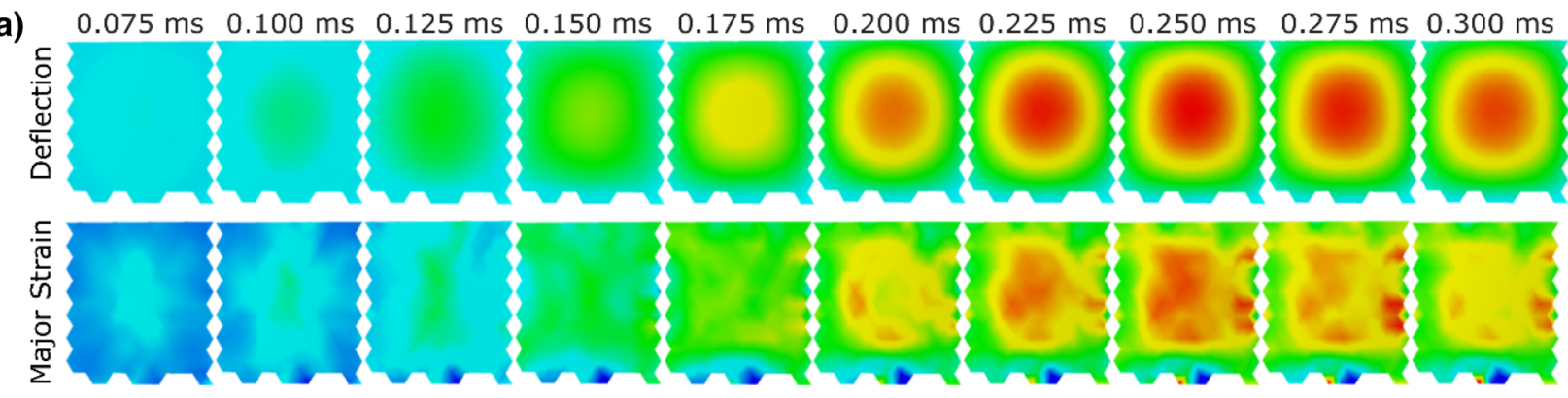

(b)
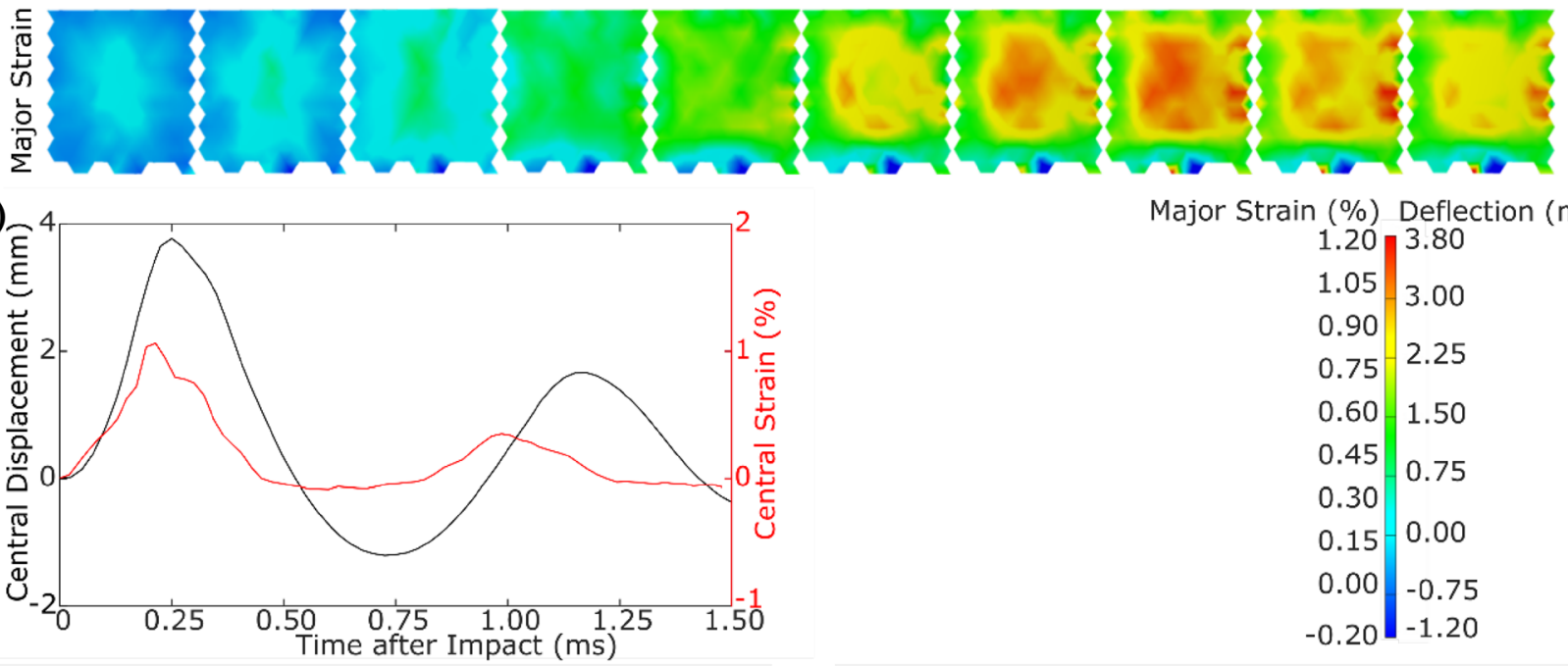

Major Strain (\%) Deflection (mm)

1.203 .80

1.053 .00

0.90

$0.75-2.25$

$0.60-1.50$

0.45

0.30

$0.15-0.00$

$0.00-0.75$

$-0.20-1.20$

(c)

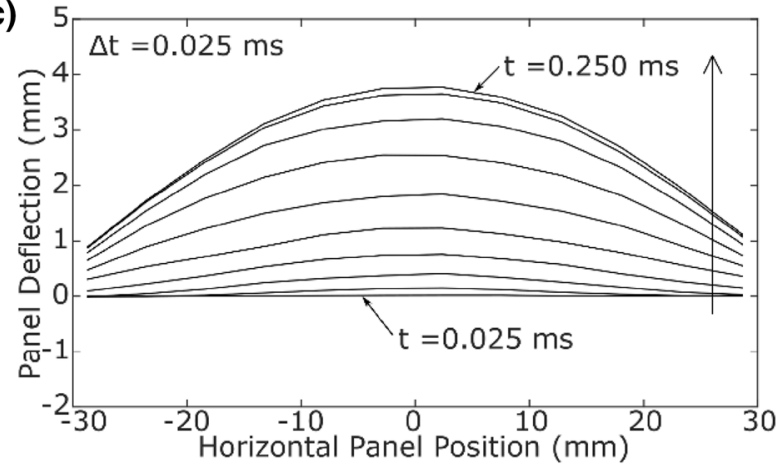

(d)

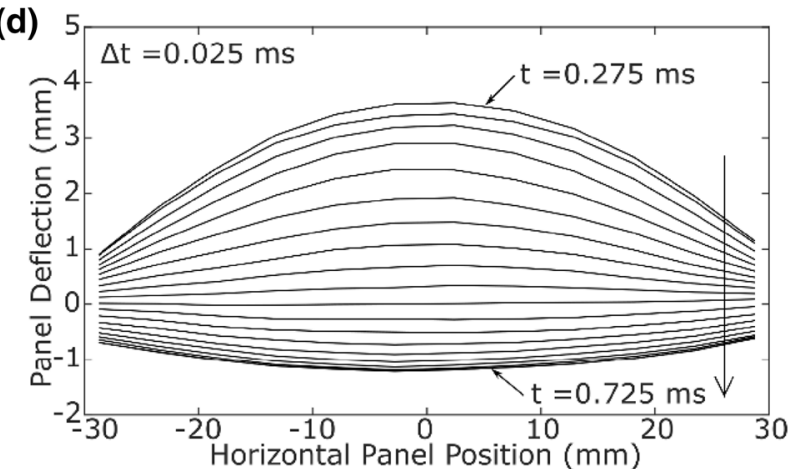

Fig. 6 DIC results for the GFRP panel under impact velocity of $75 \pm 3 \mathrm{~m} \mathrm{~s}^{-1}$ showing: a full-field deflection and major strain at time intervals, b central point deflection and major strain versus time, $\mathbf{c}$ deflection of the central horizontal section and $\mathbf{d}$ rebound of the central horizontal section

shown in Fig. 8b, may be caused by the projectile becoming embedded in the panel during the first oscillation and hence contributing towards the second deflection. The velocity of the panel during the second oscillation is lower indicating greater deflection on the second oscillation is caused by the added mass of the projectile. In addition, the damage caused by the projectile on the panel will reduce the overall panel stiffness enabling a greater second deflection. The CFRP panel demonstrated similar double peak behaviour under impact velocity $90 \mathrm{~m} \mathrm{~s}^{-1}$. In this case the projectile did not remain in the panel, however, the double peak may have been caused by a reduction in panel stiffness due to the significant damage suffered. A further repeat experiment with a front view camera would be necessary to confirm this. The velocity of Hybrid-(GCFCG) and the CFRP panel under $90 \mathrm{~m} \mathrm{~s}^{-1}$ impact is shown in Fig. 9. Under impact velocity $75 \mathrm{~m} \mathrm{~s}^{-1}$ the CFRP panel demonstrated the lowest deflection and did not rebound back to zero displacement. The Hybrid-(GCGFGCG) panel deflected further than any other hybrids when subjected to impact at $90 \mathrm{~m} \mathrm{~s}^{-1}$, maximum deflection was $3.6 \mathrm{~mm}$. This panel experienced a very slow return to the zero position after impact. When subjected to impact at $75 \mathrm{~m} \mathrm{~s}^{-1}$, the Hybrid-(GCGFGCG) panel did demonstrate negative rebound deflection as expected. Under this impact the maximum central displacement is $3.6 \mathrm{~mm}$, the maximum rebound deflection is $-0.5 \mathrm{~mm}$ and the time period for which the central displacement of the panel is positive is equal to $0.625 \mathrm{~ms}$. Hybrid-(GCGFGCG) deflected both projectiles off the front skin. This indicates that the ballistic limit for Hybrid-(GCGFGCG) is higher than the ballistic limits of Hybrid-(GCFGC) and Hybrid-(GCFCG). The extent of skin and core damage in Hybrid-(GCFGC) and Hybrid-(GCFCG) are also similar, this is discussed in further detail later. 
(a) $\quad 0.075 \mathrm{~ms} \quad 0.100 \mathrm{~ms} \quad 0.125 \mathrm{~ms} \quad 0.150 \mathrm{~ms} \quad 0.175 \mathrm{~ms} \quad 0.200 \mathrm{~ms} \quad 0.225 \mathrm{~ms} \quad 0.250 \mathrm{~ms} \quad 0.275 \mathrm{~ms} \quad 0.300 \mathrm{~ms}$

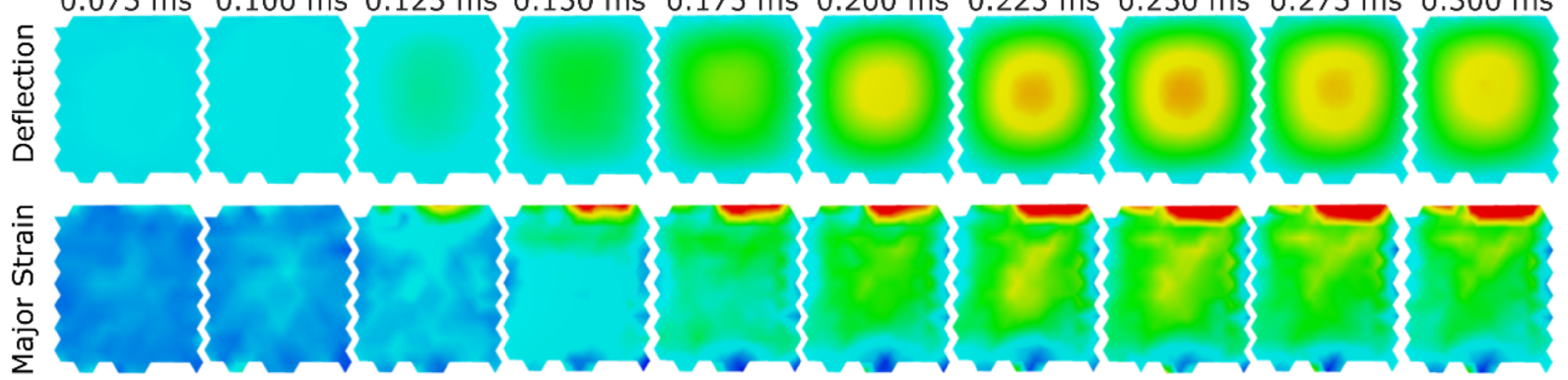

(b)

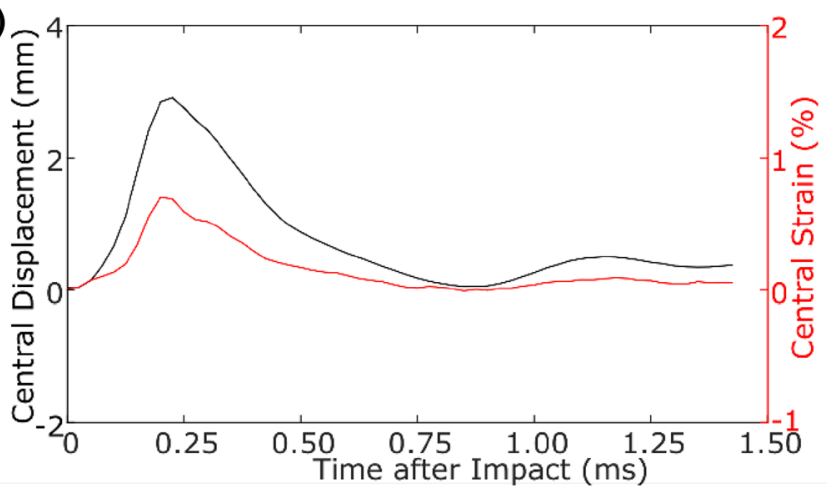

Major Strain (\%) Deflection (mm)
$1.20 \quad 3.80$
1.05
0.90
$0.75^{2.25}$
$0.60-1.50$
0.45
0.30
0.150 .00
$0.00-0.75$
$-0.20-1.20$

(c)

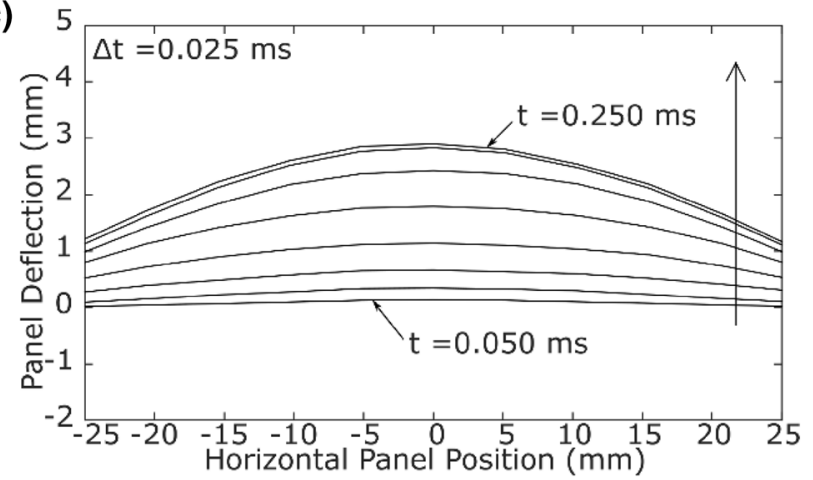

Fig. 7 DIC results for the Hybrid-(GCFGC) panel under impact velocity of $75 \pm 3 \mathrm{~m} \mathrm{~s}^{-1}$ showing: a full-field deflection and major strain at time intervals, $\mathbf{b}$ central point deflection and major strain ver- (d)

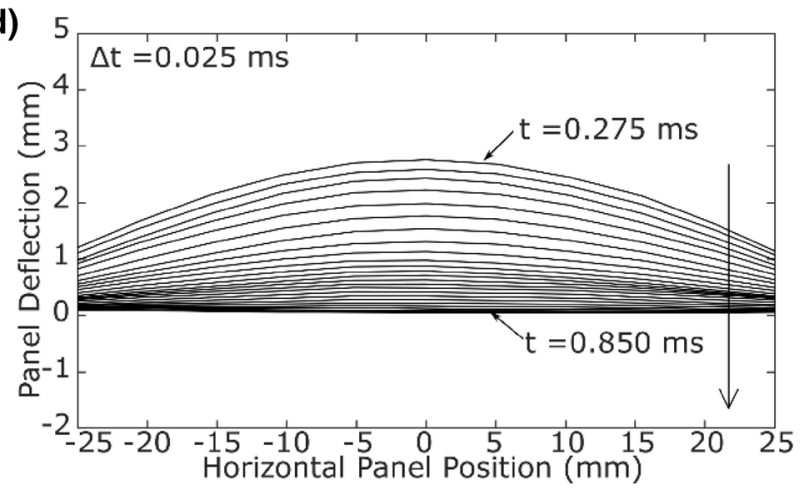

sus time, $\mathbf{c}$ deflection of the central horizontal section and $\mathbf{d}$ rebound of the central horizontal section
Fig. 8 Central point deflection versus time for impact velocity of: a $75 \pm 3 \mathrm{~m} \mathrm{~s}^{-1}$, b $90 \pm 3 \mathrm{~m} \mathrm{~s}^{-1}$ (a)

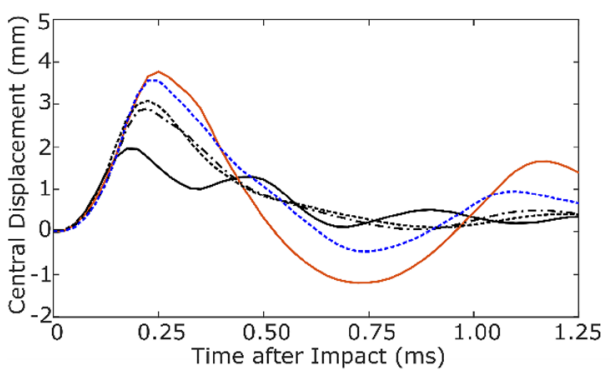

(b)

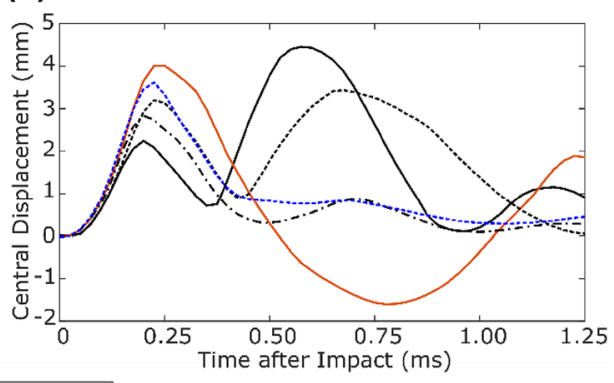

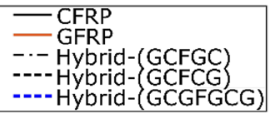




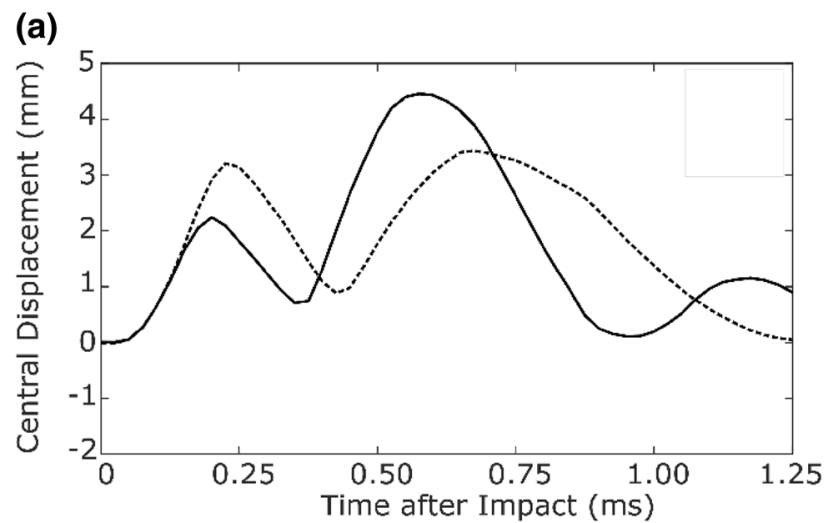

(b)

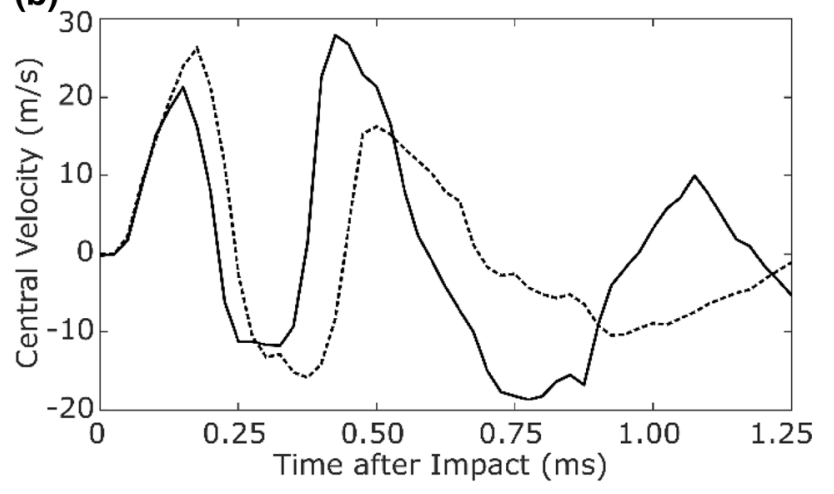

CFRP

--nybrid-(GCFCG)

Fig. 9 Central point results for: a displacement versus time and b velocity versus time for CFRP and Hybrid-(GCFCG) panels which demonstrate double displacement peak at impact velocity of $90 \pm 3 \mathrm{~m} \mathrm{~s}^{-1}$
Table 3 details the maximum deflection and strain for each panel at its centre point, along with these values normalised by the panel areal density. The lowest specific deflection is exhibited by CFRP under $75 \mathrm{~m} \mathrm{~s}^{-1}$ impact. Under impact velocity of $90 \mathrm{~m} \mathrm{~s}^{-1}$, however, the CFRP panel suffers from the greatest specific deflection and experiences major damage. Overall the lowest specific deflections are demonstrated by Hybrid-(GCFGC), this panel also exhibits the lowest specific strains, despite the coupling effect caused by asymmetry of the panel layup. The specific deflections of the GFRP panels are slightly greater than the values for the hybrid sandwich panels.

\section{Visual Damage Assessment}

Following impact testing, the panels were visually inspected for damage. Photographs of the damage to the panels under impact at $90 \mathrm{~m} \mathrm{~s}^{-1}$, including front damage and cross-section damage, are shown in Fig. 10. In addition, Table 4 details the types of damage present in each of the panels for each impact velocity along with depth of projectile penetration.

The projectiles deflected off the GFRP panels at both velocities leaving minor indentation and minor local delamination. The GFRP panels suffered from the least damage, only debonding between the core and front face-sheet. At the other extreme, the projectiles punctured the CFRP panels at both velocities and caused significant damage. The projectile travelling at $90 \mathrm{~m} \mathrm{~s}^{-1}$ damaged the rear skin of the CFRP panel. Delamination in the front skin of the CFRP panels is not visible due to the opaque black colour of the carbon-fibre plies. Delamination suffered by the hybrid front skins is extensive due to the dissimilar fibres in the hybrid skins which promotes delamination. The damage to all of the hybrid panels was quite significant, however, Hybrid(GCGFGCG) suffers from the least damage, 10 and 20\%,

Table 3 Details of the characteristics of each panel under impact

\begin{tabular}{|c|c|c|c|c|c|c|}
\hline Panel type & $\begin{array}{l}\text { Impact velocity } \\
\left(\mathrm{m} \mathrm{s}^{-1}\right)\end{array}$ & $\begin{array}{l}\text { Max centre deflec- } \\
\text { tion }(\mathrm{mm})\end{array}$ & $\begin{array}{l}\text { Max centre } \\
\text { strain }(\%)\end{array}$ & $\begin{array}{l}\text { Specific deflection } \\
\left(\mathrm{mm} \mathrm{kg}^{-1} \mathrm{~m}^{2}\right)\end{array}$ & $\begin{array}{l}\text { Specific strain } \\
\left(\% \mathrm{~kg}^{-1} \mathrm{~m}^{2}\right)\end{array}$ & $\begin{array}{l}\text { Projectile } \\
\text { embed- } \\
\text { ded }\end{array}$ \\
\hline \multirow[t]{2}{*}{ GFRP } & 78 & 3.77 & 1.06 & 0.400 & 0.113 & $\mathrm{~N}$ \\
\hline & 89 & 4.02 & 1.12 & 0.428 & 0.119 & $\mathrm{~N}$ \\
\hline \multirow[t]{2}{*}{ CFRP } & 73 & 1.96 & 0.54 & 0.194 & 0.054 & $\mathrm{~N}$ \\
\hline & 88 & $4.46^{\mathrm{a}}$ & $2.58^{\mathrm{a}}$ & 0.442 & 0.256 & $\mathrm{~N}$ \\
\hline \multirow[t]{2}{*}{ HYBRID-(GCFGC) } & 78 & 2.91 & 0.70 & 0.322 & 0.077 & $\mathrm{~N}$ \\
\hline & 89 & 2.86 & 0.71 & 0.316 & 0.079 & $\mathrm{Y}$ \\
\hline \multirow[t]{2}{*}{ HYBRID-(GCFCG) } & 78 & 3.08 & 0.81 & 0.341 & 0.090 & $\mathrm{~N}$ \\
\hline & 89 & $3.44^{\mathrm{a}}$ & $1.79^{\mathrm{a}}$ & 0.381 & 0.198 & $\mathrm{Y}$ \\
\hline \multirow[t]{2}{*}{ HYBRID-(GCGFGCG) } & 78 & 3.56 & 0.77 & 0.394 & 0.085 & $\mathrm{~N}$ \\
\hline & 89 & 3.62 & 0.96 & 0.400 & 0.106 & $\mathrm{~N}$ \\
\hline
\end{tabular}

${ }^{\mathrm{a}}$ Maximum deflection and strain from second peak 
Fig. 10 Photographs showing front skin and cross-sectional damage to sandwich panels under impact velocity of $90 \pm 3 \mathrm{~m} \mathrm{~s}^{-1}$

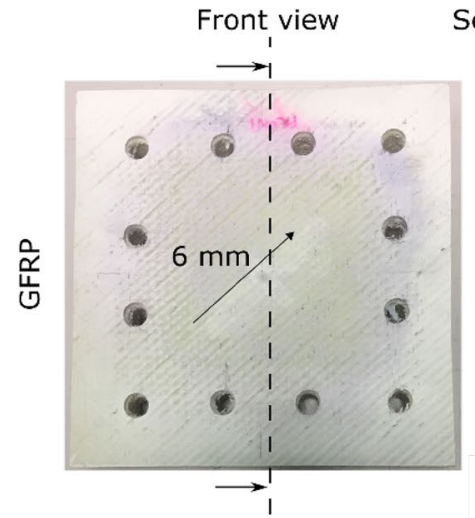

Section view
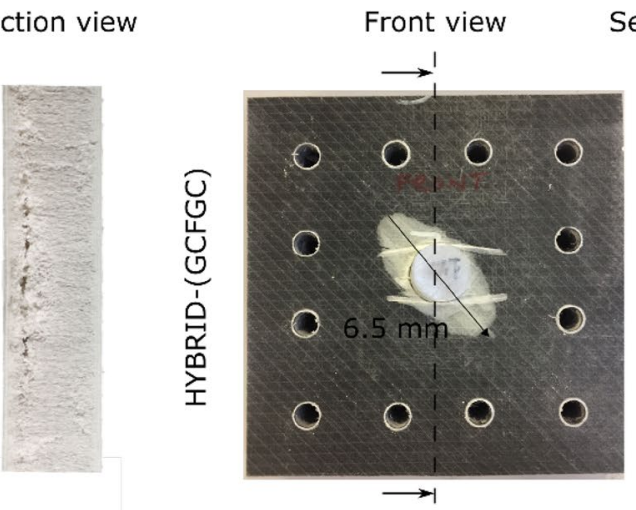

Section view
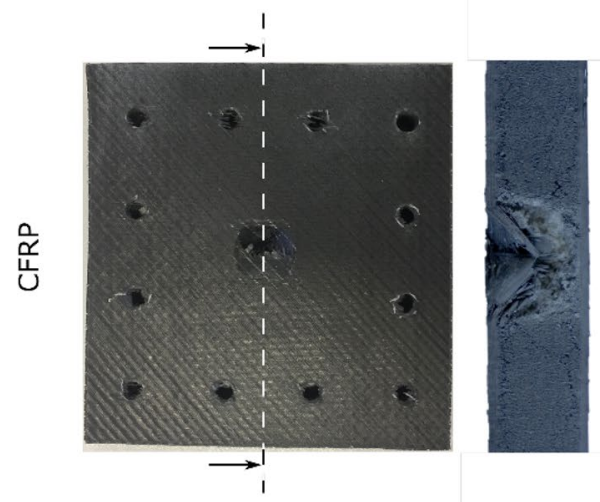
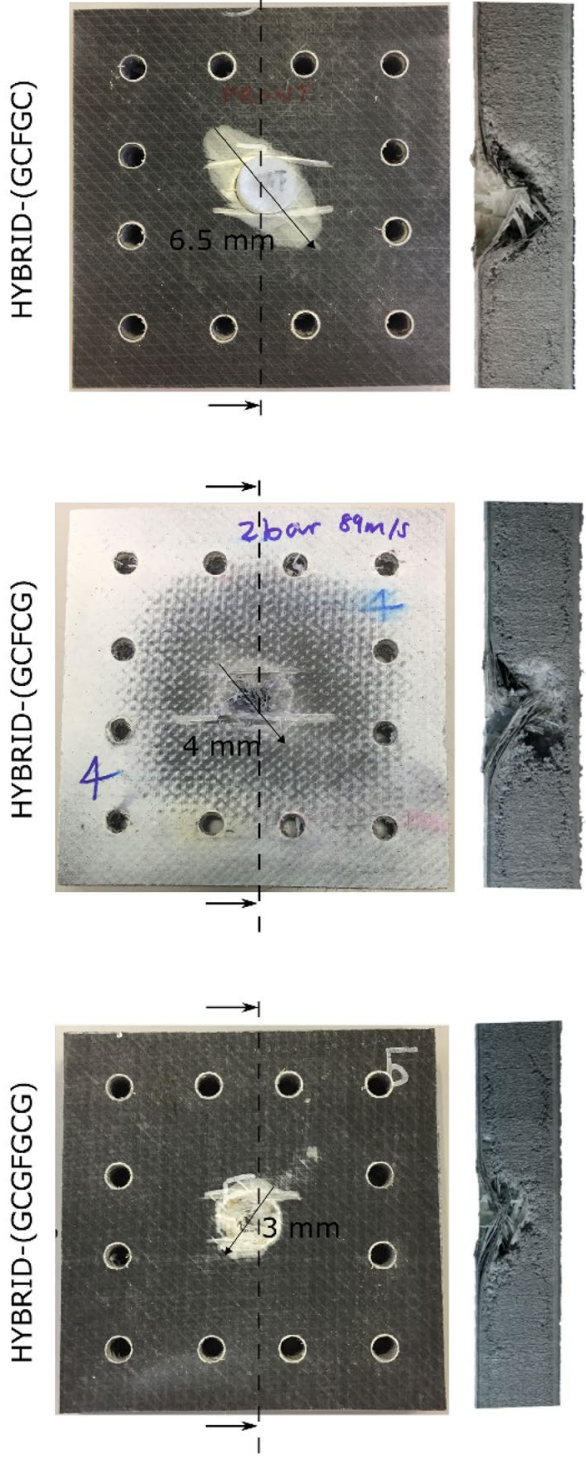

and the lowest projectile penetration, 9 and $15 \mathrm{~mm}$ under impact at 75 and $90 \mathrm{~m} \mathrm{~s}^{-1}$ respectively. The damage caused by the impacting projectiles for the Hybrid-(GCFGC) and Hybrid-(GCFCG) panels was very similar. The projectiles travelling at $75 \mathrm{~m} \mathrm{~s}^{-1}$ were deflected off the Hybrid(GCFGC) and Hybrid-(GCFCG) panels. Delamination in the front skins in a local central region and minor fibre fracture of the front-most glass fibre layers was caused. The projectiles travelling at $90 \mathrm{~m} \mathrm{~s}^{-1}$ embedded themselves into the Hybrid-(GCFGC) and Hybrid-(GCFCG) panels and caused fibre fracture in the front skins, although some glass-fibres bridged the failed region. Local central delamination in the front skins was also caused. The extent of panel damage and panel deflection is linked to the stiffness with greater stiffness resulting in lower deflection but greater damage.

\section{Blast Loading}

Hybrid-(GCFGC) demonstrated the lowest panel deflection, out of the hybrids tested, under localised impact and was, therefore, selected to undergo blast testing. Under blast loading, the panel would experience a more uniform pressure, and is therefore, expected to respond in a global manner and engage the skins and core simultaneously. Whereas under impact, the localised nature of the load engages the front skin, core and rear skin independently. In addition, the increased scale of the blast experiment is expected to result in a more global panel response. Despite these differences, the hybrid panels would be expected to exhibit a similar trend under blast and impact. Figure 11 shows DIC results for the Hybrid-(GCFGC) panel under blast loading. It is clear from Fig. 11a that the displacement of the panel, 
Table 4 Details of the damage present in each panel under impact

\begin{tabular}{|c|c|c|}
\hline & $75 \pm 3 \mathrm{~m} \mathrm{~s}^{-1}$ & $90 \pm 3 \mathrm{~m} \mathrm{~s}^{-1}$ \\
\hline GFRP & $\begin{array}{l}\text { Front skin/core debonding } \\
0 \mathrm{~mm} \text { projectile penetration } \\
0 \% \text { cross-section skin delamination }\end{array}$ & $\begin{array}{l}\text { Front skin/core debonding } \\
0 \mathrm{~mm} \text { projectile penetration } \\
0 \% \text { cross-section skin delamination }\end{array}$ \\
\hline CFRP & $\begin{array}{l}\text { Front skin/core debonding } \\
\text { Front skin delamination } \\
\text { Front skin broken fibres } \\
\text { Core crushing } \\
13 \mathrm{~mm} \text { projectile penetration } \\
21 \% \text { cross-section skin delamination }\end{array}$ & $\begin{array}{l}\text { Front skin/core debonding } \\
\text { Front skin delamination } \\
\text { Front skin broken fibres } \\
\text { Core crushing } \\
\text { Rear skin/core debonding } \\
\text { Rear skin delamination } \\
\text { Rear skin broken fibres } \\
20 \mathrm{~mm} \text { projectile penetration } \\
14 \% \text { cross-section skin delamination }\end{array}$ \\
\hline HYBRID-(GCFGC) & $\begin{array}{l}\text { Front skin/core debonding } \\
\text { Front skin delamination } \\
\text { Front skin broken fibres } \\
\text { Core crushing } \\
11 \mathrm{~mm} \text { projectile penetration } \\
17 \% \text { cross-section skin delamination }\end{array}$ & $\begin{array}{l}\text { Front skin/core debonding } \\
\text { Front skin delamination } \\
\text { Front skin broken fibres } \\
\text { Core crushing } \\
17 \text { mm projectile penetration } \\
18 \% \text { cross-section skin delamination }\end{array}$ \\
\hline HYBRID-(GCFCG) & $\begin{array}{l}\text { Front skin/core debonding } \\
\text { Front skin delamination } \\
\text { Front skin broken fibres } \\
\text { Core crushing } \\
10 \mathrm{~mm} \text { projectile penetration } \\
18 \% \text { cross-section skin delamination }\end{array}$ & $\begin{array}{l}\text { Front skin/core debonding } \\
\text { Front skin delamination } \\
\text { Front skin broken fibres } \\
\text { Core crushing } \\
\text { Rear skin/core debonding } \\
20 \mathrm{~mm} \text { projectile penetration } \\
21 \% \text { cross-section skin delamination }\end{array}$ \\
\hline HYBRID-(GCGFGCG) & $\begin{array}{l}\text { Front skin/core debonding } \\
\text { Front skin delamination } \\
9 \mathrm{~mm} \text { projectile penetration } \\
10 \% \text { cross-section skin delamination }\end{array}$ & $\begin{array}{l}\text { Front skin/core debonding } \\
\text { Front skin delamination } \\
\text { Front skin broken fibres } \\
\text { Core crushing } \\
15 \mathrm{~mm} \text { projectile penetration } \\
20 \% \text { cross-section skin delamination }\end{array}$ \\
\hline
\end{tabular}

particularly upon rebound, was asymmetrical. This is partly due to the non-uniform support from the steel test cubicle but is mainly due to the damage in the panel. This results in greater displacement and strain on the right-hand side in the final two images indicating permanent damage to the panel following blast loading. The motion of the cubicle has been removed from the DIC analysis. The sharp changes in gradient and deceleration of the panel in Fig. 11d indicate damage to the panel. The panel deflects to a maximum of $75 \mathrm{~mm}$ and rebounds to a maximum of $-24 \mathrm{~mm}$. An image of the panel following blast testing is shown in Fig. 12, along with inset images of visible core shear cracks and skin core debonding. As has been previously reported [14], the core shear damage mainly occurs at one-quarter and three-quarters across the panel width. Shear core damage is expected to occur at these width locations throughout the panel. There is no visible external damage to the panel skins. Overall the panel performs well under blast, exhibiting a similar deflection profile to those observed for the impact experiments and little post-blast damage.

\section{Discussion}

This study compared GFRP sandwich panels, CFRP sandwich panels and three hybrid composite sandwich panels under high velocity impact at $75 \pm 3$ and $90 \pm 3 \mathrm{~m} \mathrm{~s}^{-1}$. The GFRP sandwich panels suffered significantly less damage than any other panel. This is due to these GFRP panels possessing a greater areal density than the hybrid panels and a lower panel stiffness. These GFRP panels had an areal density of $9.42 \mathrm{~kg} \mathrm{~m}^{-2}$, compared to $9.04 \mathrm{~kg} \mathrm{~m}^{-2}$ of the hybrid sandwich panels. This added mass would be beneficial in preventing damage under such loading. Despite this increased mass, the GFRP panels underwent the highest deflection and greatest major strain. The glass-fibres are able to experience high deflection and strain, as shown from quasi-static experiments, due to their greater ductility and hence absorb energy in deflection rather than fracturing.

The CFRP panels suffered from the most damage, under impact at $90 \mathrm{~m} \mathrm{~s}^{-1}$ the CFRP panels suffers from high deflection and high strain due to the more brittle nature of the carbon-fibres and the high stiffness of the panel.

As expected, the damage to the hybrid panels lay between the GFRP and CFRP panels. When both impact velocities 


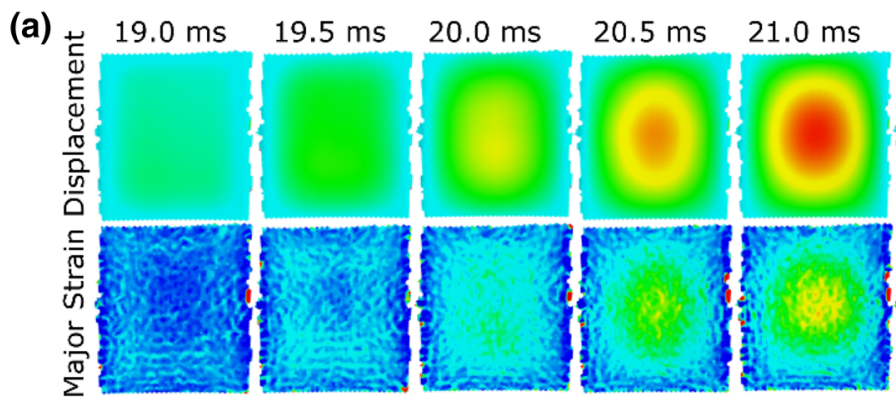

(b)

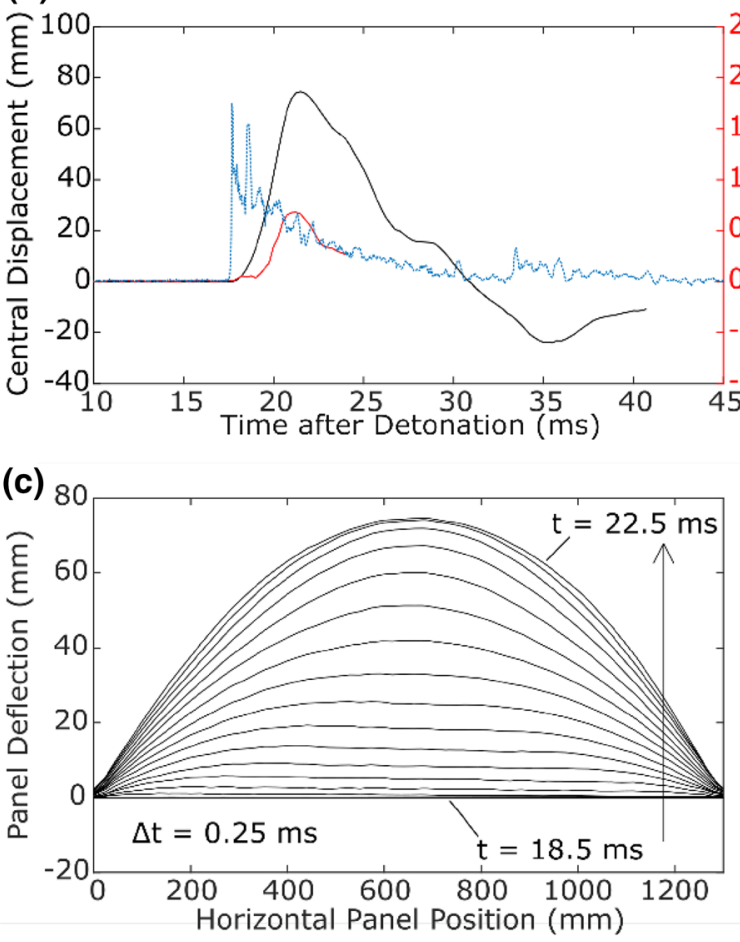

$21.5 \mathrm{~ms} \quad 22.0 \mathrm{~ms}$
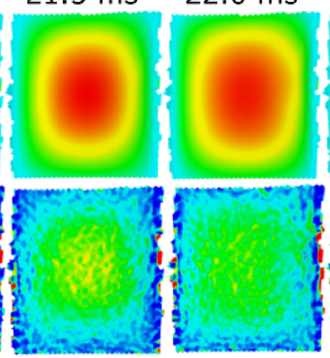

$22.5 \mathrm{~ms}$

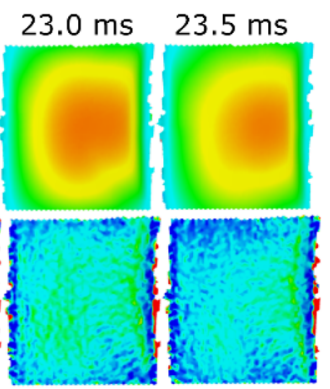

Major Strain (\%) Deflection (mm)

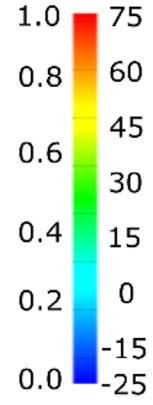

d)

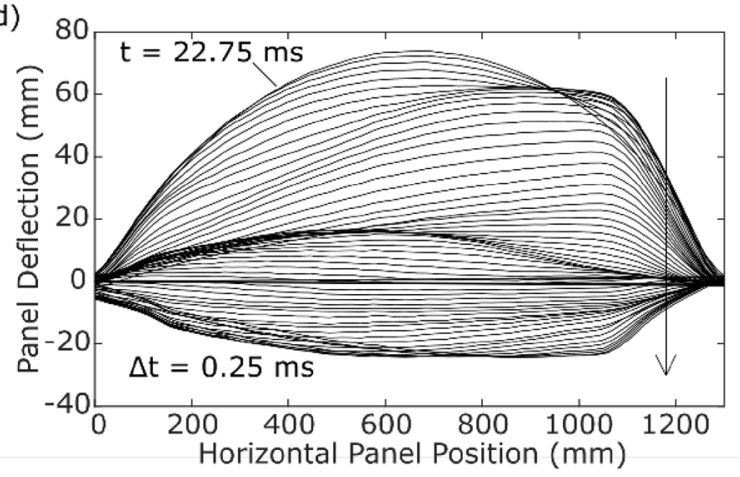

Fig. 11 DIC results for the Hybrid-(GCFGC) panel under blast loading showing: a full-field deflection and major strain at time intervals, $\mathbf{b}$ central point deflection and major strain versus time, $\mathbf{c}$ deflection of the central horizontal section and $\mathbf{d}$ rebound of the central horizontal section

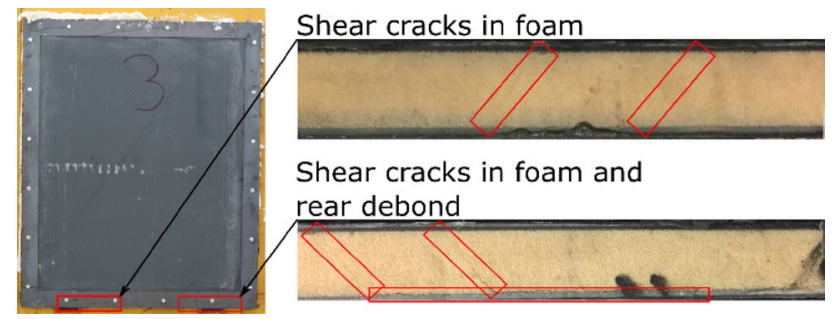

Fig. 12 Photograph of front skin of Hybrid-(GCFGC) panel immediately following blast loading and inset images of damage in foam core

are considered, the hybrids exhibited lower deflection and lower strain than either the GFRP or CFRP panels. The higher stiffness of the panels and lower strain to failure are caused by the carbon-fibre layers included in the layup. When the areal density is taken into consideration, as detailed in Table 3, the hybrids still demonstrate lower deflection and strain compared to the GFRP or CFRP panels. Due to the dissimilar layers of carbon-fibre and glass-fibre present in the hybrid panels and their differing properties, the hybrid panels are more prone to delamination especially between these dissimilar materials [5]. As reported in literature, greater damage, including delamination, results in more energy dissipation [7]. This accounts for the lower deflection and strains recorded for the hybrid panels at the expense of significant damage.

The symmetrical panel (Hybrid-(GCFCG)) suffers 1-3\% more damage and $0.11-1.08 \%$ greater major strain than the asymmetrical panel, Hybrid-(GCFGC). Furthermore, the symmetrical panel demonstrates a double deflection and strain peak under impact at $90 \mathrm{~m} \mathrm{~s}^{-1}$. If the direction of 
loading is known, it would be beneficial to select an asymmetrical panel. If a symmetric panel is required, for example if the direction of loading is unknown, a more dispersed hybridisation offers advantages. Hybrid-(GCGFGCG) suffers from less surface damage than the other hybrids, particularly under impact at $75 \mathrm{~m} \mathrm{~s}^{-1}$. The panel experienced up to $3.5 \mathrm{~mm}$ less front-skin delamination, shown in Fig. 10, and low projectile penetration. Under impact at $90 \mathrm{~m} \mathrm{~s}^{-1}$ the dispersed hybrid, Hybrid-(GCGFGCG) has a $0.83 \%$ lower major strain than Hybrid-(GCFCG). Although the lower stiffness of the panel results in higher deflection and strain, this is compensated by the reduced panel surface damage. Further testing of these panels to determine the ballistic limits along with energy absorption and compression under impact would be recommended to further compare the performance of these hybrid layups.

Hybrid-(GCFGC) demonstrated the lowest deflection under localised impact and was, therefore, subjected to full-scale blast loading. The panel performed well against a $100 \mathrm{~kg}$ nitromethane charge. DIC analysis of the panel shows that there is certainly damage to the core and interface between the skins and core. Visual inspection of the panel following blast has shown there is no external damage to the skins. This highlights that there are significant differences between impact and blast loading. Impact loading creates a localised load. This causes front skin fracture along with significant penetration damage to the foam core. Far-field explosive blast testing results in a more uniform pressure load across the front of the panel. This enables the panel to respond and deform globally. It is, therefore, important to test representative materials under both blast and impact loading if they are expected to undergo such loading types.

\section{Conclusions}

These experiments have demonstrated the ability of simple hybrid composite sandwich panels to resist impact and blast loads. In addition, the position of the carbon-fibre and glass-fibre layers has been shown to affect the panel response under impact loading demonstrating that hybrid composite sandwich panels should be tailored for specific applications. High-speed DIC techniques were employed to monitor the deformation of the targets during both impact and blast. The difference between the two loading types has been highlighted by these studies. Impact loading results in a localised force hence causes localised damage. Under impact all panels suffered from front skin damage and core damage. Far-field blast enables a global response and no front skin damage was observed for the panel subjected to this type of loading. The following bullet points summarise the main findings from the experiments performed in this research.
- Due to the dissimilar layers of carbon-fibre and glassfibre present in the hybrid panels and their differing properties, the hybrid panels are more prone to subsurface delamination. The hybrid panels suffer from 18 to $21 \%$ cross-sectional skin delamination. The hybrid panels demonstrate a clear trade-off between deflection and damage.

- If the direction of impact loading is known, it would be beneficial to select an asymmetrical panel tailored to the expected load direction. The asymmetrical panel, Hybrid-(GCFGC) exhibits a specific deflection of $0.322 \mathrm{~mm} \mathrm{~kg}^{-1} \mathrm{~m}^{2}$ and specific strain $0.077 \% \mathrm{~kg}^{-1} \mathrm{~m}^{2}$ under impact velocity $75 \mathrm{~m} \mathrm{~s}^{-1}$, the lowest for any panel at this impact velocity.

- If a symmetric panel is required, selection of a panel with a symmetric yet more dispersed hybridisation would be effective. The more dispersed hybrid, Hybrid-(GCGFGCG), has a specific deflection of $0.394 \mathrm{~mm} \mathrm{~kg}^{-1} \mathrm{~m}^{2}$ and specific strain $0.085 \% \mathrm{~kg}^{-1} \mathrm{~m}^{2}$ under impact velocity $75 \mathrm{~m} \mathrm{~s}^{-1}$.

- Placing carbon-fibre layers closer to the impact skin, however not as the impact skin itself, results in less surface delamination. Hybrid-(GCGFGCG), which has carbon-fibre layers closest to the surface, suffers $3 \mathrm{~mm}$ of surface delamination under impact velocity of $90 \mathrm{~m} \mathrm{~s}^{-1}$.

- Hybrid-(GCFGC) performs well under full-scale blast conditions, with a maximum deflection of $75 \mathrm{~mm}$ following a similar deflection profile to that observed for the impact experiments. The skins remain intact although there is internal panel damage. The combination of dissimilar materials does not result in a loss of panel integrity but rather could be adapted for different applications.

Acknowledgements The authors would like to thank Dr Yapa Rajapakse of the Office of Naval Research (N62909-15-1-2004, N0001408-1151 and N00014-12-1-0403) for supporting Emily Rolfe, Dr Mark Kelly and Dr Hari Arora during their PhDs and EPSRC for supporting Emily Rolfe during her $\mathrm{PhD}$. The testing opportunity provided by CPNI along with the support and assistance from GOM UK (Amy Johnson), Slowmo Ltd (Mark Johnson), DNV GL, Alexander Sancho, Jun Liu and Charlotte Baumhauer is very much appreciated.

Open Access This article is distributed under the terms of the Creative Commons Attribution 4.0 International License (http://creativeco mmons.org/licenses/by/4.0/), which permits unrestricted use, distribution, and reproduction in any medium, provided you give appropriate credit to the original author(s) and the source, provide a link to the Creative Commons license, and indicate if changes were made.

\section{References}

1. Karthikeyan K, Russell BP, Fleck NA et al (2013) The soft impact response of composite laminate beams. Int J Impact Eng 60:2436. https://doi.org/10.1016/j.ijimpeng.2013.04.002 
2. Czél G, Wisnom MR (2013) Demonstration of pseudo-ductility in high performance glass/epoxy composites by hybridisation with thin-ply carbon prepreg. Compos Part A 52:23-30. https://doi. org/10.1016/j.compositesa.2013.04.006

3. Swolfs Y, Gorbatikh L, Verpoest I (2014) Fibre hybridisation in polymer composites: a review. Compos Part A 67:181-200. https ://doi.org/10.1016/j.compositesa.2014.08.027

4. Bouwmeester JGH (2008) Carbon/Dyneema Intralaminar Hybrids: new strategy to increase impact resistance or decrease mass of carbon fiber composites. In: 26th congress of the international council of the aeronautical sciences

5. Sevkat E, Liaw B, Delale F, Raju BB (2009) Drop-weight impact of plain-woven hybrid glass-graphite/toughened epoxy composites. Compos Part A 40:1090-1110. https://doi.org/10.1016/J. COMPOSITESA.2009.04.028

6. Enfedaque A, Molina-Aldareguía JM, Gálvez F et al (2010) Effect of glass fiber hybridization on the behavior under impact of woven carbon fiber/epoxy laminates. J Compos Mater 44:3051-3068. https://doi.org/10.1177/0021998310369602

7. Sevkat E, Liaw B, Delale F, Raju BB (2010) Effect of repeated impacts on the response of plain-woven hybrid composites. Compos Part B 41:403-413. https://doi.org/10.1016/J.COMPOSITES B.2010.01.001

8. Pandya KS, Pothnis JR, Ravikumar G, Naik NK (2013) Ballistic impact behavior of hybrid composites. Mater Des 44:128-135. https://doi.org/10.1016/j.matdes.2012.07.044

9. Reddy PRS, Reddy TS, Mogulanna K et al (2017) Ballistic impact studies on carbon and E-glass fibre based hybrid composite laminates. Procedia Eng 173:293-298. https://doi.org/10.1016/J. PROENG.2016.12.017

10. Randjbaran E, Zahari R, Abdul Jalil NA, Abang Abdul Majid DL (2014) Hybrid composite laminates reinforced with kevlar/ carbon/glass woven fabrics for ballistic impact testing. Sci World J 2014:413753. https://doi.org/10.1155/2014/413753

11. Arora H, Hooper P, Del LP et al (2012) Modelling the behaviour of composite sandwich structures when subject to air-blast loading. Int J Multiphys 6:199-218. https://doi. org/10.1260/1750-9548.6.3.199

12. Rolfe E, Kelly M, Arora $\mathrm{H}$ et al (2017) Failure analysis using X-ray computed tomography of composite sandwich panels subjected to full-scale blast loading. Compos Part B 129:26-40. https ://doi.org/10.1016/j.compositesb.2017.07.022

13. Arora $\mathrm{H}$ (2012) Blast loading of fibre reinforced polymer composite structures. Imperial College London, London

14. Kelly M, Arora H, Worley A et al (2015) Sandwich panel cores for blast applications: materials and graded density. Exp Mech. https://doi.org/10.1007/s11340-015-0058-5

15. Gardner N, Wang E, Kumar P, Shukla A (2012) Blast mitigation in a sandwich composite using graded core and polyurea interlayer. Exp Mech 52:119-133. https://doi.org/10.1007/s1134 0-011-9517-9

16. Gurit (2015) Datasheet/PRIMETM 20LV, pp 1-6. http://www.gurit .com/sitecore/content/Old-Product-Pages/Other-Products/Lamin ating-Infusion-Systems/PRIME-20LV

17. AZoM.com Limited E-glass fibre. https://www.azom.com/prope rties.aspx?ArticleID=764

18. Minus M, Kumar S (2005) The processing, properties, and structure of carbon fibers. JOM 57:52-58. https://doi.org/10.1007/ s11837-005-0217-8

19. Armacell Benelux SA ArmaFORM PET/W GR. https://local .armacell.com/en/armaform-pet-foamcores/download/products/

20. GOM mbH (2013) Aramis user manual—software. GOM mbH, Braunschweig 